\title{
CRIAÇÃO DE SPIN-OFFS ACADÊMICOS: UMA ANÁLISE DOS CRITÉRIOS DETERMINANTES DE DESEMPENHO
}

CREATION OF ACADEMIC SPIN-OFFS: AN ANALYSIS OF

KEY-PERFORMANCE CRITERIA

\section{Priscila Nesello}

Universidade Federal de Pelotas. Professora. E-mail: pri.nesello@gmail.com.

\section{Rodrigo Marques de Almeida Guerra}

Universidade Federal do Pará. Professor. E-mail: rmaguerra1@gmail.com.

\section{Thiarlei Machado Macedo}

Centro Universitário UniFtec. Professor. E-mail: thiarlei@enttry.com.br.

\section{Paula Patrícia Ganzer}

Faculdade CNEC Farroupilha. Professora. E-mail: ganzer.paula@gmail.com.

\section{Maria Emilia Camargo}

Universidade de Caxias do Sul. Professora. E-mail: mariaemiliappga@gmail.com.

\section{Pelayo Munhoz Olea}

Universidade Federal do Rio Grande. Professor. E-mail: pelayo.olea@gmail.com.

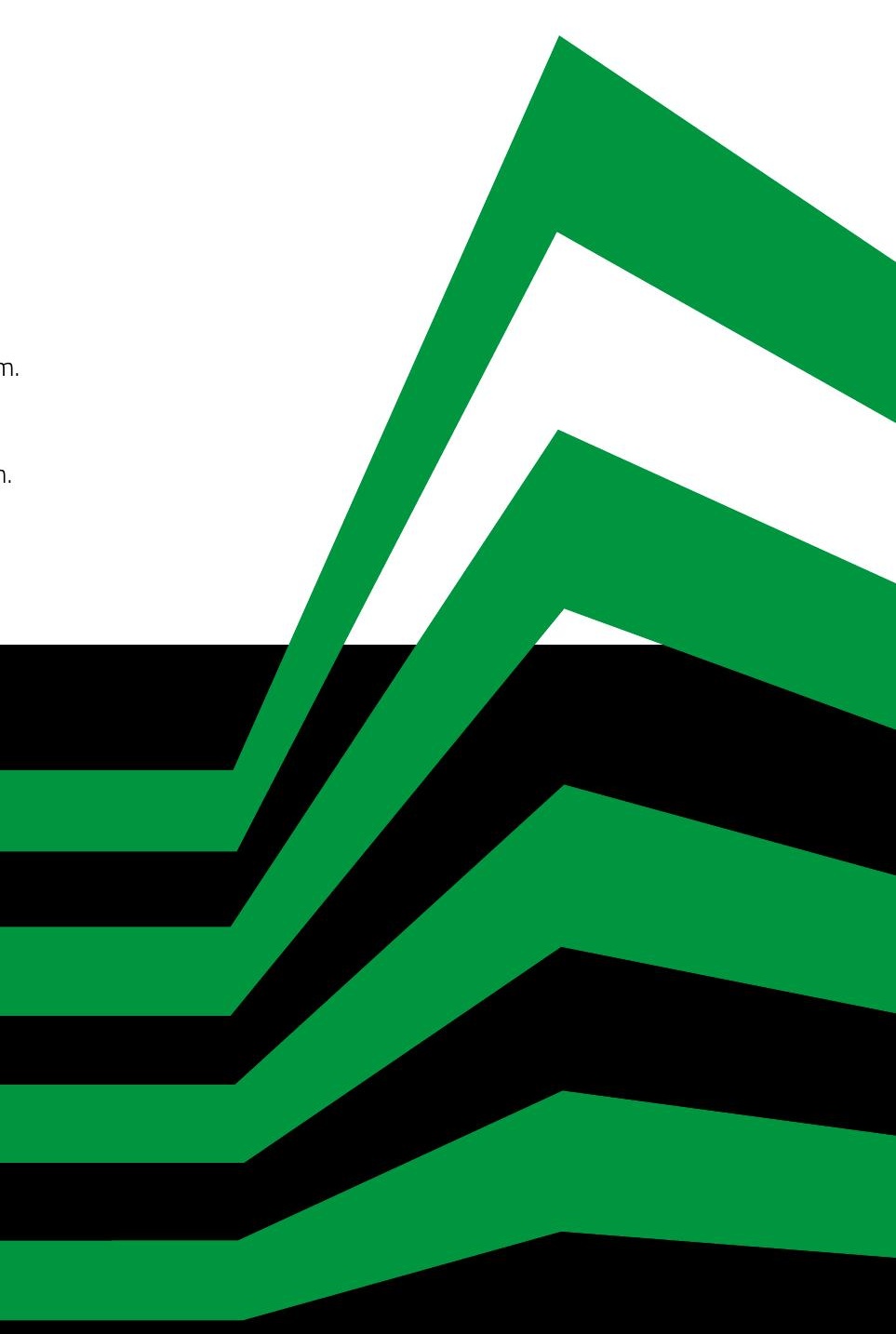




\section{RESUMO}

No Brasil, as taxas de sobrevivência do empreendedorismo de alto impacto estão abaixo das taxas de sobrevivência de empresas de outros setores, mesmo com o incentivo de programas governamentais e o apoio de entidades de fomento. Diante disso, este artigo teve como objetivo analisar os critérios determinantes do desempenho inicial de spin-offs acadêmicos pré-incubados, no contexto da tomada de decisão relacionada ao investimento inicial. Para tanto, procedeu-se a uma análise baseada nas oito variáveis utilizadas no modelo apresentado por De Coster e Butler (2005), que representam, atualmente, o estado da arte no que diz respeito aos fatores determinantes do desempenho inicial de spin-offs acadêmicos pré-incubados. Os resultados encontrados foram, então, comparados com os achados de um estudo realizado no Reino Unido, país referência em empreendedorismo e inovação. Quanto ao método de coleta e análise dos dados, realizou-se uma pesquisa quantitativa, por meio de uma survey com 43 alunos do curso de Análise e Desenvolvimento de Sistemas de uma faculdade do Estado do Rio Grande do Sul, região com as maiores taxas de sobrevivência de empresas no país. A aplicação da análise fatorial exploratória indicou como determinantes para o desempenho inicial de spin-offs o risco tecnológico e comercial, o nível de inovação de produto e o modo de satisfação de setor do mercado. Além disso, observou-se que o critério significativo mais distintivo na comparação com o Reino Unido foi a existência de família de produtos, aspecto ausente no cenário investigado neste estudo.

Palavras-chave: Startup. Inovação. Sobrevivência de empresas.

\section{ABSTRACT}

In Brazil, survival rates of high-impact entrepreneurship are below the survival rates of firms in other sectors, even with the encouragement of government programs and support from development agencies. The objective of this article was to analyze the criteria determining the initial performance of pre-incubated academic spin-offs in the context of decision-making related to the initial investment. For that, an analysis based on the eight variables used in the model presented by De Coster and Butler (2005), that represent, at the moment, the state of the art with respect to the determinants of the initial performance of academic spin-offs pre-incubated. The results were then compared with the findings of a study in the United Kingdom, a reference country in entrepreneurship and innovation. As for the method of data collection and analysis, a quantitative survey was carried out, through a survey of 43 students from the Analysis and Systems Development course at a university in the state of Rio Grande do Sul, the region with the highest rates of survival of companies in the country. The application of the exploratory factorial analysis indicated as determinants for the initial performance of spin-offs the technological and commercial risk, the level of product innovation and the mode of satisfaction of the market sector. In addition, it was observed that the most distinctive criterion in the comparison with the United Kingdom was the existence of family of products, aspect absent in the scenario investigated in this study. Keywords: Startup. Innovation. Survival companies. 


\section{INTRODUÇÃo}

Anualmente, empresas no Brasil são criadas a partir da coragem de empreendedores que sonham em ter seu próprio negócio. Sendo a academia parte importante do processo de transferência de tecnologia (CARAYANNIS et al., 1998; STEFFENSEN; ROGERS; SPEAKMAN, 1999; MUSTAR et al., 2006), surgem as spin-offs acadêmicas, as quais podem dar origem a startups, empresas que constituem 0 empreendedorismo de alto impacto (RIES, 2011). De acordo com Ries (2011), startup é uma instituição formada por pessoas e projetada para criar e entregar um novo produto ou serviço sob condições de extrema incerteza (RIES, 2011). Essas empresas de base tecnológica são consideradas um dos principais motores de mudança e crescimento econômico (BATHELT; KOGLER; MUNRO, 2010), pois permitem a geração e transferência de conhecimento e inovação tecnológica de produtos e serviços (RIES, 2011).

Nesse contexto, ao iniciar um novo negócio, o empreendedor precisa analisar a necessidade de investimento de risco e a capacidade da organização de se manter com seus próprios recursos, com recursos dos sócios, com receitas provenientes das vendas ou com linhas de crédito existentes, por exemplo. Nos casos em que a empresa tem necessidade de buscar recursos, são comuns múltiplas rodadas de financiamento sob a forma de Venture Capital para levar a empresa de seu estágio inicial até a liquidez (GOMPERS, 1995).

As duas maiores fontes de Venture Capital para novos negócios com alto potencial de crescimento são os investidores-anjo (mercado informal de Venture Capita) e os fundos de Venture Capital (mercado formal de Venture Capitah. O termo "anjo" é comumente utilizado para definir o "Investidor Informal Privado", uma vez que o anjo investe seus próprios recursos financeiros e humanos em empresas privadas, tipicamente nos estágios iniciais, instaurando negócios com alto potencial de crescimento (valorização), mas também com altos riscos (BOTELHO; DIDIER; RODRIGUEZ, 2006). Esse investimento é feito em troca de participação societária temporária e preferencial, associada a uma expectativa de ganho de capital expressivo na venda futura de sua participação, em montante compativel com o risco assumido (BOTELHO; DIDIER; RODRIGUEZ, 2006).

De acordo com dados apresentados pela entidade Anjos do Brasil (2015), uma organização sem fins lucrativos, criada para fomentar o crescimento do investimento-anjo no país, o investimento-anjo destinado a startups cresceu 11\% entre 2013 e 2014, somando R\$ 688 milhões. Por parte do governo, projetos como o TI maior, Programa Estratégico de Software e Serviços de Tecnologia da Informação, tentam estimular o desenvolvimento de softwares, com investimentos na ordem de R\$500 milhões até 2015. Nesse cenário, é importante que sejam desenvolvidos projetos para empreendimentos de base tecnológica, observando-se os fatores determinantes para o desempenho. 
Assim, uma vez que spin-offs acadêmicas podem dar origem a startups e que existe interesse pelo desenvolvimento desse tipo de empreendimento, com vistas a promover as transformações necessárias para o desenvolvimento econômico nacional, torna-se importante analisar os critérios determinantes do desempenho inicial de spin-offs acadêmicas pré-incubadas. Adicionalmente, investidores têm interesse em aplicar seus recursos em startups (ANJOS DO BRASIL, 2015), porém, faltam oportunidades para investimento em iniciativas de empresas inovadoras. Nesse sentido, este estudo contribui para identificar os pontos de alavancagem necessários para transformar os projetos desenvolvidos nas universidades em futuros empreendimentos, promovendo a aproximação da pesquisa acadêmica com as atuais demandas da sociedade.

Para isso, foi realizada uma pesquisa com 43 alunos do curso de Análise e Desenvolvimento de Sistemas de uma faculdade situada em Caxias do Sul, Rio Grande do Sul. Essa cidade apresenta, segundo o Serviço Brasileiro de Apoio às Micro e Pequenas Empresas (SEBRAE, 2013), a maior taxa de sobrevivência do empreendedorismo de alto impacto do estado, com 83\%, justificando, assim, sua escolha para a execução deste estudo. Para isso, foi utilizado o instrumento de pesquisa desenvolvido por De Coster e Butler (2005), que contempla oito variáveis indicativas dos fatores determinantes para avaliação de propostas de novos empreendimentos de base tecnológica. Esse instrumento de pesquisa foi aplicado pelos autores no Reino Unido, país referência em empreendedorismo e inovação, e fundamentado, de acordo com Freitas et al. (2011), nos principais trabalhos precedentes, tornando as oito variáveis utilizadas no modelo o estado da arte no que diz respeito a fatores apontados como determinantes do desempenho inicial de spin-offs acadêmicas pré-incubadas.

A fim de explicitar a pesquisa realizada, este artigo é composto por quatro seções, além desta introdutória. Na segunda seção, apresenta-se o referencial teórico, que aborda os temas sobrevivência de empresas no Brasil, cenário das startups brasileiras, empreendedorismo e inovação e spin-offs acadêmicas. Já na terceira seção, expõe-se a metodologia da pesquisa, em que são descritos os procedimentos de coleta e análise dos dados. Na quarta seção, constam a análise e discussão dos resultados. E, por fim, na quinta seção, abordam-se as considerações finais, juntamente com as limitações da pesquisa e sugestões de estudos futuros.

\section{REFERENCIAL TEÓRICO}

A fundamentação teórica apresentada neste estudo trata dos temas sobrevivência de empresas no Brasil, cenário das startups brasileiras, empreendedorismo e inovação e spin-offs acadêmicas. 


\subsection{SOBREVIVÊNCIA DE EMPRESAS NO BRASIL}

O crescimento do número de empresas gera impactos positivos para o país, como aumento da competitividade e maior oferta de empregos. Entretanto, sua sustentabilidade em longo prazo requer o acompanhamento de órgãos de apoio a esses empreendimentos. É indispensável, assim, monitorar não apenas a criação de empresas, como também a taxa de sobrevivência dos novos negócios.

De acordo com um relatório desenvolvido pelo Sebrae (2013), nos últimos anos o Brasil tem experimentado um aumento na criação de novas empresas. Mudanças políticas em favor dos pequenos negócios contribuíram para esse fato, a exemplo da criação da Lei Geral das Micro e Pequenas Empresas em 2006, da implantação do Microempreendedor Individual (MEI) em 2009 e da ampliação dos limites de faturamento do Simples Nacional ${ }^{1}$ em 2012. A Figura 1, a seguir, apresenta a evolução da taxa de sobrevivência de empresas no Brasil de 2005 a 2007.

Figura 1: Taxa de sobrevivência de empresas no Brasil

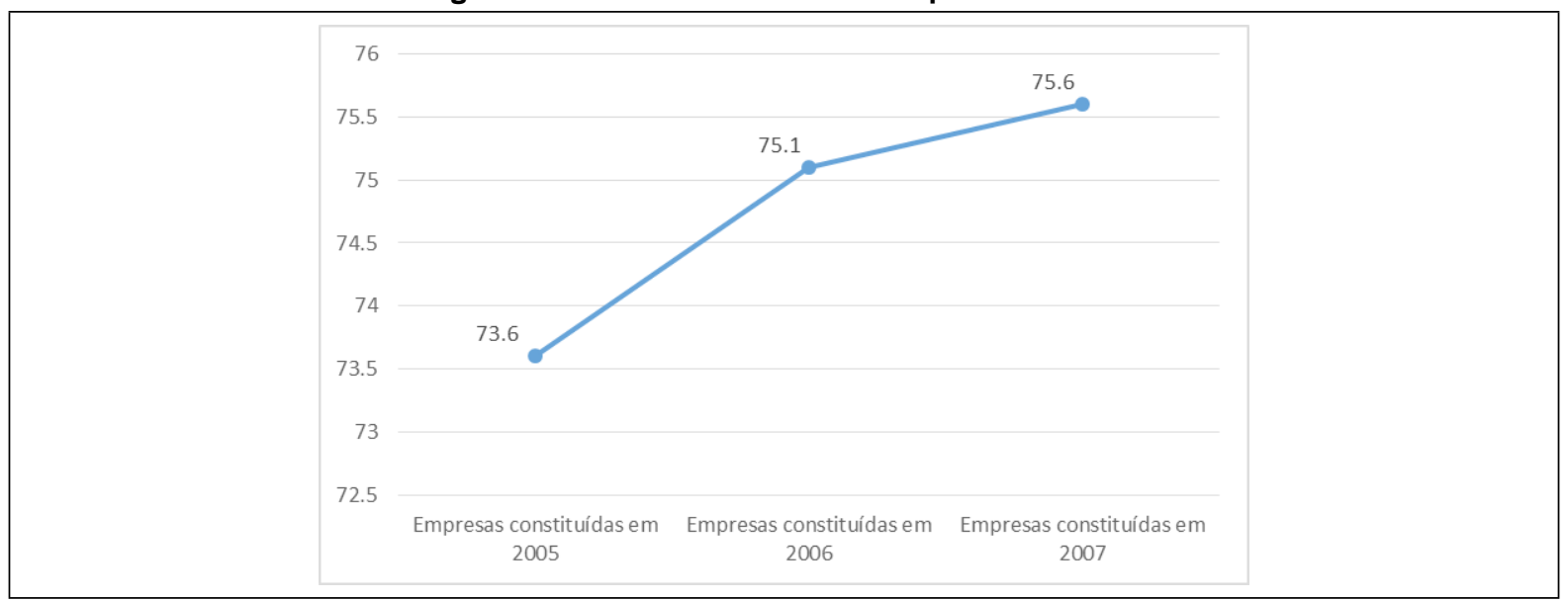

Fonte: Sebrae (2013).

Percebe-se, dessa forma, de acordo com a Figura 1, que empresas brasileiras constituídas em 2007 têm uma taxa de sobrevivência de 75,6\%, número que representa um modesto crescimento de dois pontos percentuais em relação às empresas brasileiras constituídas em 2005. No Reino Unido, segundo o Department of Trade and Industry (DTI, 2003 apud De Coster e Butler, 2005), as chances de uma empresa sobreviver por três anos ou mais aumentou de 60 para $64 \%$ entre 1993 e 2000. Dados internacionais mais

\footnotetext{
${ }^{1}$ Simples Nacional: regime fiscal diferenciado e favorável aos pequenos negócios.
} 
recentes a esse respeito são expostos na Figura 2, que traz as taxas de sobrevivência de empresas com até dois anos (criadas em 2007) e com empregados (em \%).

Figura 2: Taxas de sobrevivência de empresas com dois anos e com empregados

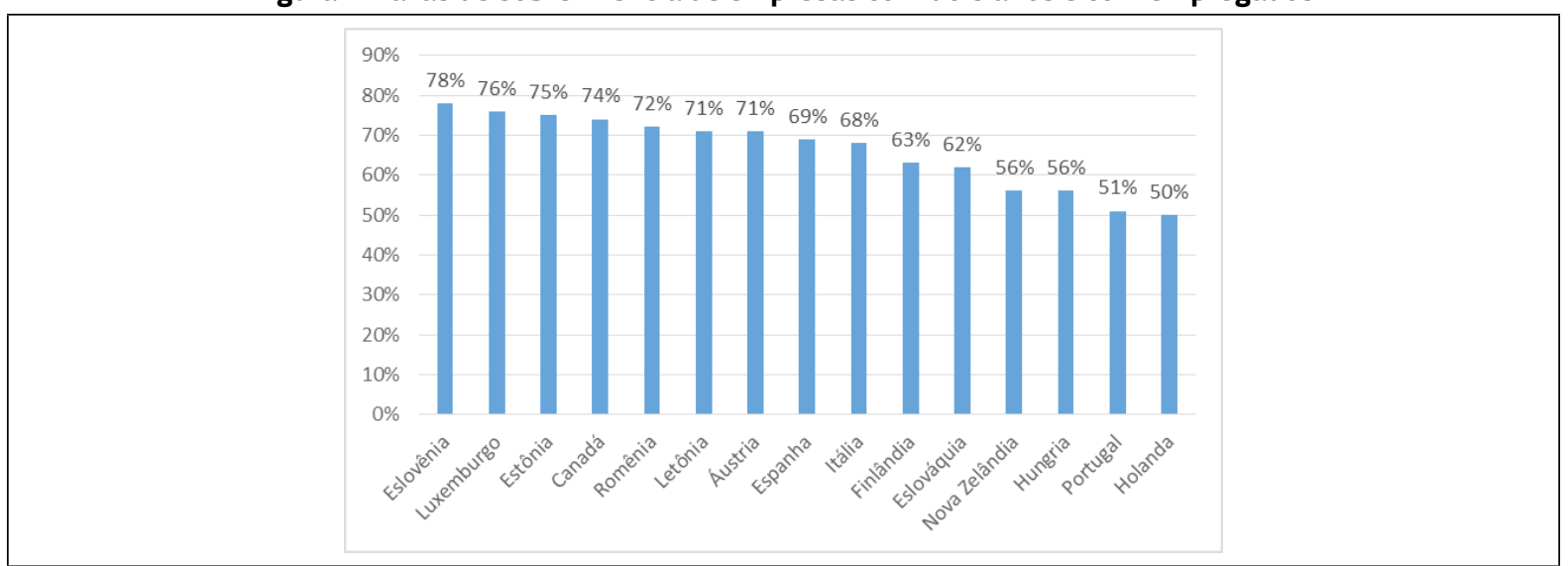

Fonte: Organization for Economic Co-operation and Development (OECD, 2013 apud SEBRAE, 2013).

No Brasil, nas regiões Sudeste e Sul, a taxa de sobrevivência de empresas chega a 83,2\% e 81,4\%, respectivamente, representando as maiores taxas do país. A cidade de Caxias do Sul, no Rio Grande do Sul, é a que apresenta a maior taxa de sobrevivência do estado, com 83\% (1.986 empresas constituídas em 2007) (SEBRAE, 2013).

De acordo com o Sebrae (2013), o setor industrial é o que apresenta maior taxa de sobrevivência $(79,9 \%)$, seguido pelo comércio $(77,7 \%)$, pela construção $(72,5 \%)$ e pelos serviços $(72,2 \%)$. Isso pode ser explicado pelo fato de que o setor industrial enfrenta maiores barreiras de entrada e menor pressão da concorrência, ao contrário de requisitos de capital, tecnologia e conhecimento técnico (SEBRAE, 2013).

No setor industrial, a taxa de sobrevivência de empresas que atuam na fabricação de equipamentos de informática e de produtos eletrônicos e ópticos é de 86\% (262 empresas constituídas em 2007) - taxa elevada se comparada a outros segmentos, como o da fabricação de bebidas, por exemplo, com 59\% (300 empresas constituídas em 2007). Uma explicação para o bom desempenho desse segmento é que tende a incorporar maior conteúdo de inovações associadas às novas Tecnologias de Informaç̧ão e Comunicação (TICs), apresentando maior potencial de diferenciação de produtos e serviços, e que constitui um segmento cuja demanda tende a crescer de forma paralela ao crescimento da renda e do grau de escolaridade da população (SEBRAE, 2013). 


\subsection{CENÁRIO DAS STARTUPS BRASILEIRAS}

No que concerne especificamente às startups, entre 2012 e 2013, o investimento-anjo cresceu 25\% no Brasil, somando R $\$ 619$ milhões. Esses dados foram apresentados durante a 2a Conferência Nacional de Investimento-Anjo, promovida pela Anjos do Brasil, uma associação que reúne investidores com o objetivo de fomentar o crescimento do empreendedorismo de inovação no Brasil (ANJOS DO BRASIL, 2015). Já o crescimento do número de investidores foi menos expressivo nesse período, totalizando apenas 2,3\%. Dados de 2013 retratam que, embora investidores tivessem interesse em aplicar até R\$ 208 mil ao ano em startups, faltavam oportunidades para investimento em iniciativas de empresas inovadoras. Entre as áreas mais procuradas para o desenvolvimento dessas iniciativas, estavam tecnologia da informação e biotecnologia.

Dados da $3^{\text {a }}$ Conferência Nacional de Investimento-Anjo, também promovida pela Anjos do Brasil, evidenciam que, de 2013 a 2014, houve um crescimento de 11\% em relação ao período de 2012 e 2013 (ANJOS DO BRASIL, 2015), confirmando um investimento em startups no Brasil na ordem de R\$ 688 milhões. O número de investidores-anjo, por sua vez, cresceu 9\% nesse período. Apesar de esse tipo de investimento ter apresentado uma expansão de 0,6\% do Produto Interno Bruto (PIB) em 1999 para 2,1\% em 2013, em outros países ele chega a ser o dobro: um exemplo é Reino Unido, em que esse tipo de investimento equivale a $4,7 \%$ do $\mathrm{PIB}^{2}$. Dados mais recentes apontam que a quantidade de investidoresanjo no Brasil cresceu 16\% em 2017 em relação a 2016. Atualmente, o país abriga um total de 7.615 investidores-anjo.

Em virtude disso, os incentivos por parte do governo procuram apoiar empreendedores em suas iniciativas de novos negócios na área de tecnologia. Programas como o TI maior objetivam estimular o desenvolvimento de softwares no Brasil (CRUZ, 2012). Lançado no ano de 2012, com um investimento previsto de $\mathrm{R} \$ 500$ milhões até 2015, o programa tem como pilares: desenvolvimento econômico e social; posicionamento internacional; inovação e empreendedorismo; produção científica e tecnológica e inovação; e competitividade.

Em conformidade com o pensamento de Bathelt, Kogler e Munro (2010), Meyer (2012) reafirma que as startups têm potencial para mudar a curva de uma economia inteira. Contudo, para que isso ocorra, é necessário que consigam se manter no mercado. De acordo com uma pesquisa de Nogueira e Arruda (2015), os dados referentes ao tempo médio de sobrevivência de startups no Brasil indicam que: pelo

\footnotetext{
2 Fonte: Como encontrar um investidor anjo para o meu negócio? Disponível em: <https: http://exame.abril.com.br/pme/noticias/ como-encontrar-um-investidor-anjo-para-o-meu-negocio>. Acesso em: 05/08/2016.
} 
menos 25\% das startups morrem em um tempo menor que um ano; pelo menos 50\% das startups morrem em um tempo menor que quatro anos; e pelo menos $75 \%$ das startups morrem em um tempo menor que treze anos. Esses números refletem a fragilidade de startups no que se refere à taxa de sobrevivência, abaixo das taxas nacionais e setoriais de sobrevivência de startups.

Nogueira e Arruda (2015) identificaram, ainda, três aspectos significativos que influenciam a mortalidade de startups. Entre eles estão: o número de sócios envolvidos, o volume de capital investido e o local de instalação da startup. Além disso, a análise de dados realizada pelos autores revelou que o fato de uma startup estar instalada em uma aceleradora, em uma incubadora ou em um parque tecnológico representa um fator de proteção para sua sobrevivência.

\subsection{EMPREENDEDORISMO E INOVAÇÃO}

Uma inovação é a implementação de um produto (bem ou serviço) novo ou significativamente melhorado, ou de um processo, de um novo método de marketing ou de um novo método organizacional nas práticas de negócios, na organização do local de trabalho ou nas relações externas. Assim, enquanto a inovação tecnológica se refere à inovação de produto e processo, as inovações não tecnológicas dizem respeito à inovação organizacional e de marketing (OECD, 2005).

Nesse contexto, identificam-se dois elementos básicos para a inovação (BESSANT; TIDD, 2009). 0 primeiro é a capacidade de desenvolver conhecimento científico, característica associada principalmente às infraestruturas e ao pessoal de universidades e instituições de ciência e tecnologia. O segundo é a capacidade de converter esse conhecimento em tecnologia presente em produtos comercializáveis junto ao mercado, aspecto que se encontra fortemente relacionado às empresas. Da compreensão desses elementos básicos, surge o desafio de transformar o conhecimento científico e tecnológico existente em universidades e centros de pesquisa em conhecimento disponibilizado pelas empresas na forma de produtos acessiveis ao mercado (BESSANT; TIDD, 2009).

De acordo com Bessant e Tidd (2009), muito do que se sabe atualmente sobre empreendimentos inovadores vem da experiência norte-americana em empresas de software, biotecnologiae semicondutores. Os autores esclarecem que essas empresas são criadas a partir de organizações-mãe ou "incubadoras", geralmente instituições acadêmicas ou empresas estabelecidas. Como exemplos de universidades incubadoras, citam-se a Universidade de Stanford, que gerou o Vale do Silício; o Instituto de Tecnologia de Massachusetts (MIT), que gerou o Route 128, em Boston; o Imperial College London; e a Universidade de Cambridge, no Reino Unido. 
Conforme Piscione (2014), o Vale do Silício transformou-se no principal polo de inovação do mundo. Originado na Universidade de Stanford, na Califórnia, contou com um investimento inicial de US\$ 5 milhões. No papel de reitor, Frederick Terman fortaleceu a cultura empreendedora ao estimular discentes e docentes a montarem suas próprias empresas em detrimento da carreira acadêmica. Em 1946, Terman criou o Parque Industrial Stanford, que foi a base para a aproximação entre a universidade e a indústria (PISCIONE, 2014). Ele também estimulava professores a atuarem como consultores pagos por corporações, aproximando ainda mais a academia e o setor privado, por acreditar que isso auxiliaria os docentes a se manterem atualizados sobre as necessidades das empresas e funcionaria como um instrumento para facilitar o financiamento de pesquisas e parcerias aos alunos (PISCIONE, 2014). Atualmente, o Parque de Pesquisas Stanford abriga cerca de 150 empresas.

Com uma longa tradição na geração de empresas spin-offs, a Route 128, situada em Cambridge, Boston, nos Estados Unidos, teve origem nos investimentos militares em computação e software, ajudando a criar incubadoras de empresas como Compaq, Digital, Data General, Lucent, Lotus, Raytheon e Wang. Recentemente, tem estabelecido negócios de base científica na área de artefatos médicos e de biotecnologia. A Route 128 inclui o MIT, a Universidade de Harvard, a Universidade de Boston e outras 70 universidades e faculdades (BESSANT; TIDD, 2009).

A agência de inovação do Imperial College, por sua vez, foi fundada em 1986, no Reino Unido, com a missão de transformar a pesquisa acadêmica em produtos rentáveis e benéficos. São atividades que compõem sua estratégia: identificar tecnologias interna e externamente; avaliar a viabilidade comercial dessas iniciativas; fornecer aconselhamento para patenteamento e licenciamento; e apoiar a formação de novas empresas e a captação de investimento.

Por fim, a Universidade de Cambridge, fundada em 1970, tem sua estratégia de atuação focada em serviços de transferência de tecnologia, consultoria e gerenciamento de capital. Em 2008, foi eleita como melhor escritório de transferência de tecnologia britânico (BESSANT; TIDD, 2009).

A partir desses exemplos, é possivel perceber que as universidades têm importante papel na produção do conhecimento científico e tecnológico e na formação de recursos humanos compatíveis com uma economia baseada em conhecimento (VENKATARAMAN, 2003; SAEMUNDSSON, 2004; SANTOS; CUNHA, 2004; ARIAS; VALBUENA, 2007; DAHLSTRAND, 2007). Essas instituições passaram, ao longo do tempo, por transformações, a exemplo da incorporação de novos papéis que historicamente eram vinculados às empresas e ao governo. Assim, tem emergido desse processo uma terceira missão atribuída às universidades: a inovação (aplicação do conhecimento em produtos e processos), que vem se somar às atividades tradicionais de produção e difusão do conhecimento (pesquisa e ensino) (CLARK, 2003; CLARK, 2004). 
Entretanto, conforme evidencia o estudo de Desidério e Zilber (2014), há algumas barreiras no processo de transferência tecnológica entre agências de inovação e empresas. Os autores esclarecem que essas barreiras são partes incorporadas ao processo de transferibilidade, ocorrendo apesar dos incentivos promovidos pela lei da inovação e das intenções das universidades, dos centros de pesquisa e das entidades de fomento. Entre as principais barreiras identificadas por Desidério e Zilber (2014) estão os recursos, a conexão com o mercado, os problemas de interação e a estrutura reduzida.

Em complemento, Bessante Tidd (2009) explicitam que determinadas empresas não são inovadoras, pois alguns empresários objetivam alcançar a independência financeira e não criar negócios inovadores. Nesse sentido, os autores categorizam os diferentes motivos e mecanismos do empreendedorismo, citando, entre eles, os empreendedores "como um modo de vida", os empreendedores do crescimento e os empreendedores inovadores.

Os empreendedores "como um modo de vida" são aqueles que procuram independência e desejam ganhar a vida com base nas suas possibilidades e nos seus valores (lojas ou empresas de consultoria). Já os empreendedores do crescimento são aqueles que têm como objetivo se tornarem ricos e poderosos por meio da criação e do crescimento de seus negócios (varejo, imóveis e bens - commodities). E os empreendedores inovadores, por seu turno, são aqueles guiados pelo desejo de criar ou mudar algo, independentemente do seu setor de atuação.

Na visão de Bessant e Tidd (2009), existem, ainda, os empreendedores sociais e os empreendedores tecnológicos. Os empreendedores sociais visam criar valor e mudança social, em vez de inovação comercial e valor financeiro, necessitando, para isso, do envolvimento de organizações privadas, públicas e do terceiro setor. Já os empreendedores tecnológicos baseiam sua decisão de iniciar um novo empreendimento no desejo de ganhar independência e fugir da burocracia de grandes organizações. Conforme Bessant e Tidd (2009), o nível de instrução, o perfil psicológico, a experiência de trabalho e a técnica contribuem para a decisão de criar um empreendimento.

Enquanto na Route 128, a experiência de trabalho do empreendedor é vinculada com uma empresa incubadora apenas, no Vale do Silício os empreendedores técnicos tendem a obter experiência em muitas empresas antes de estabelecerem seus próprios negócios. No Reino Unido, a ênfase está no apoio ao empreendedor para a criação do negócio, etapa em que incidem os maiores riscos.

Em ambos os casos, o suporte de uma organização-mãe está presente na etapa de criação do novo empreendimento (TUMELERO; MARINS; CARNAÚBA, 2011). Essa é a essência de pertencer a incubadoras tecnológicas, pois tais empresas, quando incubadas, desfrutam da oportunidade de serem apoiadas por habitats de inovação, mobilizando esforços para a articulação de redes de conhecimento endógenas e exógenas em seu ambiente de incubação (TUMELERO; MARINS; CARNAÚBA, 2011). 


\subsection{SPIN-OFFS ACADÊMICAS}

Spin-offs acadêmicas, spin-outs ou startups são consideradas os principais motores da mudança e do crescimento econômico (BATHELT; KOGLER; MUNRO, 2010), pois permitem a geração e transferência do conhecimento e a inovação tecnológica de produtos e serviços desenvolvidos, geralmente, com o suporte de uma organização-mãe no ambiente universitário (CARAYANNIS et al., 1998; STEFFENSEN; ROGERS; SPEAKMAN, 1999; MUSTAR et al., 2006). A spin-off beneficia-se, assim, da capacidade de investigação regional e da formação avançada de seu pessoal técnico na geração de produtos inovadores (BATHELT; KOGLER; MUNRO, 2010), por meio da transferência de tecnologia (CARAYANNIS et al., 1998; MUSTAR et al., 2006).

A transferência de tecnologia via spin-offcontribui para o papel da universidade no desenvolvimento econômico da região em que está inserida (STEFFENSEN; ROGERS; SPEAKMAN, 1999). Dois fatores são importantes na formação de spin-offs: i) geralmente um empresário é transferido de uma organizaçãomãe; e ii) a tecnologia utilizada no novo empreendimento também é incorporada de uma organizaçãomãe (CARAYANNIS et al., 1998).

A atividade de spin-off está relacionada ao comportamento empreendedor de seus fundadores e colaboradores (ITURRIAGA; CRUZ, 2008; BATHELT; KOGLER; MUNRO, 2010), surgindo, muitas vezes, a partir de critérios do mercado, mediante a geração de conhecimento e a inovação de produtos e serviços, possibilitando, dessa forma, a obtenção de vantagem competitiva em relação aos concorrentes (DE COSTER; BUTLER, 2005; ITURRIAGA; CRUZ, 2008). As spin-offs podem ser geradas de duas maneiras: planejada - um novo empreendimento resultante de um esforço feito pela organização-mãe, mantendo, frequentemente, uma estreita relação com essa organização-mãe durante e após o processo de spinoff; e espontânea - uma nova empresa criada por um empreendedor que identifica uma oportunidade de mercado e estabelece a spin-off, sendo, usualmente, pouco incentivada pela organização-mãe (STEFFENSEN; ROGERS; SPEAKMAN, 1999).

Cabe ressaltar, ainda, conforme menciona Sternberg (2014), que o contexto regional em que um empreendedor cria uma spin-off tem impacto sobre seu sucesso, de modo que o apoio do governo possui menor relevância do que a influência gerada pelo contexto regional. Pérez e Sánchez (2003), por sua vez, sugerem que uma das contribuições do empreendedorismo de alta tecnologia das empresas consiste em seu papel catalisador para a criação e transferência de conhecimento em redes de inovação.

Para Bathelt, Kogler e Munro (2010), empreendimentos de tecnologia têm a capacidade de atrair o interesse de outras empresas regionais, nacionais ou internacionais. Todavia, a criação de spin-offs é menor em períodos de recuperação econômica do que em períodos de crescimento econômico estável (ERIKSSON; KUHN, 2006). 
Cleyn, Braet e Klofsten (2015) realizaram entrevistas pessoais com 185 spin-offs acadêmicas orientadas para produtos em nove países europeus. Os resultados mostram um impacto positivo significativo, mas decrescente, da heterogeneidade da equipe no sucesso do empreendimento, bem como um impacto positivo da expertise jurídica no conselho de administração. No que concerne à gestão, os resultados indicam, ainda, que uma equipe de gerenciamento maior está mais bem preparada para enfrentar os desafios de uma spin-off. Além disso, os autores questionam o valor agregado dos empreendedores em série, uma vez que eles parecem impactar negativamente as chances de sobrevivência desses empreendimentos. É preciso, assim, lidar com uma composição de equipe apropriada aos níveis da alta administração e do conselho de administração, bem como prestar atenção no desenvolvimento da equipe (DE CLEYN; BRAET; KLOFSTEN, 2015).

Nesse cenário, as universidades criam spin-offs acadêmicas como uma estratégia para comercializar inovações produzidas por meio de pesquisas. Por sua natureza, as spin-offs caracterizam-se como empreendimentos arriscados que, muitas vezes, falham em alcançar um nível adequado de desempenho (POPONI; BRACCINI; RUGGIERI, 2017).

Diante disso, Poponi, Braccini e Ruggieri (2017) identificaram nove fatores associados ao desempenho positivo em spin-offs: start-up premiada, heterogeneidade de habilidades dos fundadores, acesso ao financiamento, riqueza ambiental, capital de rede, tamanho relativo, confiabilidade, inovatividade e motivação para se aventurar.

\section{METODOLOGIA}

Para a realização da pesquisa, foi utilizada uma abordagem quantitativa, de caráter descritivo (HAIR Jr. et al., 2009), a fim de analisar os critérios determinantes do desempenho inicial de spin-offs acadêmicas pré-incubadas. Os dados foram coletados no mês de dezembro de 2014 mediante formulário desenvolvido na plataforma Google Forms, sendo convidados a participar 116 alunos formados no curso de Análise e Desenvolvimento de Sistemas, no período de 2011 a 2014. Os respondentes da pesquisa, 43 egressos, responderam questões em relação ao produto gerado a partir de seus trabalhos de conclusão de curso.

O instrumento de coleta de dados foi construído com base na escala de De Coster e Butler (2005). Em seu estudo, os autores compararam 14 novas spin-offs acadêmicas de base tecnológica e 14 empresas da comunidade com relação às variáveis de fatores determinantes para avaliação de propostas para novos empreendimentos de base tecnológica. Para que fosse utilizada nesta pesquisa, a escala passou pelo processo de tradução reversa. Assim, seguindo as orientações de Hill e Hill (2012), duas traduções da 
escala foram produzidas separadamente por especialistas em inovação fluentes em inglês e português. Por meio da comparação dos itens traduzidos para o inglês com os itens originais, verificou-se a fidelidade da escala em português em relação à escala desenvolvida por De Coster e Butler (2005). A Tabela 1, exposta a seguir, apresenta os oito critérios utilizados como variáveis e seus objetivos.

Tabela 1: Critérios determinantes do desempenho inicial de spin-offs acadêmicas pré-incubadas

\begin{tabular}{|c|c|}
\hline Variável & Objetivo \\
\hline Risco tecnológico e comercial & $\begin{array}{l}\text { Avaliar a efetividade do funcionamento do produto e a viabilidade de sua } \\
\text { produção }\end{array}$ \\
\hline Nivel de inovação de produto & $\begin{array}{l}\text { Avaliar o grau de inovação do produto e a força da concorrência no } \\
\text { mercado }\end{array}$ \\
\hline Modo de satisfação de setor do mercado & $\begin{array}{l}\text { Avaliar como o produto/serviço atende à(s) demanda(s) de um setor de } \\
\text { mercado e qual é o tamanho do mercado }\end{array}$ \\
\hline Momento de mercado & $\begin{array}{l}\text { Avaliar o momento do mercado-alvo em relação às condições } \\
\text { macroeconômicas que o influenciam e suas tendências }\end{array}$ \\
\hline Longevidade e repetibilidade de compras & Avaliar a repetibilidade da compra e a longevidade do produto \\
\hline Existência de família de produtos & $\begin{array}{l}\text { Avaliar se a tecnologia pode ser incorporada, não somente a um único } \\
\text { produto, mas também a uma família de produtos, a fim de permitir a } \\
\text { consolidação e o desenvolvimento da empresa }\end{array}$ \\
\hline Histórico dos empreendedores & Avaliar o histórico de inovação e a equipe do projeto \\
\hline Proteção de vantagem competitiva & $\begin{array}{l}\text { Avaliar o nível de propriedade intelectual do processo, da tecnologia e } \\
\text { dos produtos desenvolvidos ou em desenvolvimento }\end{array}$ \\
\hline
\end{tabular}

Fonte: Freitas et al. (2010 apud De Coster e Butler, 2005).

As questões foram, então, mensuradas por escala Likert de 5 pontos, por intermédio da identificação dos dois pontos-fim, ou seja, da menor posição credivel de um empreendimento em fase inicial (1 ponto) e do melhor concebível (5 pontos). A escala para o ponto médio (3 pontos) foi criada para representar o estado mediano de uma nova empresa de tecnologia. Após a aplicação dos questionários, procedeu-se à análise fatorial das respostas, com auxílio do software SPSS Statistics 20, com o intuito de identificar pesos para os construtos de acordo com a percepção dos respondentes acerca de seus projetos.

Em seguida, foi aplicado o método de ponderação proposto por De Coster e Butler (2005), uma vez que nem todos os parâmetros são considerados como de importância igual ou independentes uns dos outros. Posteriormente, os valores ponderados foram somados para chegar ao resultado de cada 
avaliação, que suportava um máximo de 50 pontos. Os valores ponderados também foram multiplicados em conjunto e divididos pelo resultado de 15.000 para obter o produto em escala. Essas ponderações são exemplificadas na Tabela 2.

Tabela 2: Exemplo de uma avaliação

\begin{tabular}{|l|l|l|l|}
\hline \multicolumn{1}{|c|}{ Critérios } & \multicolumn{1}{|c|}{ Pontuação } & \multicolumn{1}{c|}{$\begin{array}{c}\text { Ponderação por } \\
\text { critério }\end{array}$} & \multicolumn{1}{c|}{$\begin{array}{c}\text { Pontuação ponde- } \\
\text { rada }\end{array}$} \\
\hline Risco tecnológico e comercial & 2 & 3 & 6 \\
\hline Nível de inovação de produto & 5 & 2 & 10 \\
\hline Modo de satisfação de setor do mercado & 3 & 1 & 3 \\
\hline Momento de mercado & 5 & 1 & 5 \\
\hline Longevidade e repetibilidade de compras & 5 & 0,5 & 2,5 \\
\hline Existência de família de produtos & 3 & 0,5 & 1,5 \\
\hline Histórico dos empreendedores & 3 & 1 & 3 \\
\hline Proteção de vantagem competitiva & 2 & 1 & 2 \\
\hline SOMA & & & 33 \\
\hline PRODUTO EM ESCALA & & & 1,35 \\
\hline
\end{tabular}

Fonte: Elaborado a partir de De Coster e Butler (2005).

Conforme De Coster e Butler (2005), em alguns casos, a soma pode ser considerada satisfatória, mas o produto em escala não. Isso ocorrerá se as pontuações individuais forem amplamente dispersas, o que evidencia áreas de fraqueza nos projetos. Assim, um parâmetro aproximado para essa análise consiste em uma pontuação de 25 pontos para a soma e 25 pontos para o produto em escala, indicando que a proposta técnica é forte o suficiente para considerar o financiamento. Levando tais aspectos em consideração, após efetuar as análises, os resultados obtidos neste estudo foram comparados aos achados do trabalho de De Coster e Butler (2005) no Reino Unido.

\section{ANÁLISE E DISCUSSÃO DOS RESULTADOS}

O objetivo deste estudo foi analisar os critérios determinantes do desempenho inicial de spin-offs acadêmicas pré-incubadas. Para atender a esse objetivo, as respostas de 43 egressos do curso de Análise 
e Desenvolvimento de Sistemas sobre o produto gerado a partir de seus trabalhos de conclusão de curso foram coletadas e analisadas sob a luz dos oito fatores apontados como determinantes do desempenho inicial de spin-offs acadêmicas pré-incubadas.

A análise dos dados é apresentada, a seguir, com base na frequência das respostas por critério, na análise fatorial dos critérios, na avaliação da soma da pontuação e do produto em escala, nos resultados comparativos pela média da pontuação com as spin-offs acadêmicas do Reino Unido e, por fim, no teste de significância (teste $t$ ). Os resultados de maior frequência para os critérios determinantes do desempenho inicial de spin-offs acadêmicas pré-incubadas, de acordo com os respondentes, são apresentados na Figura 3.

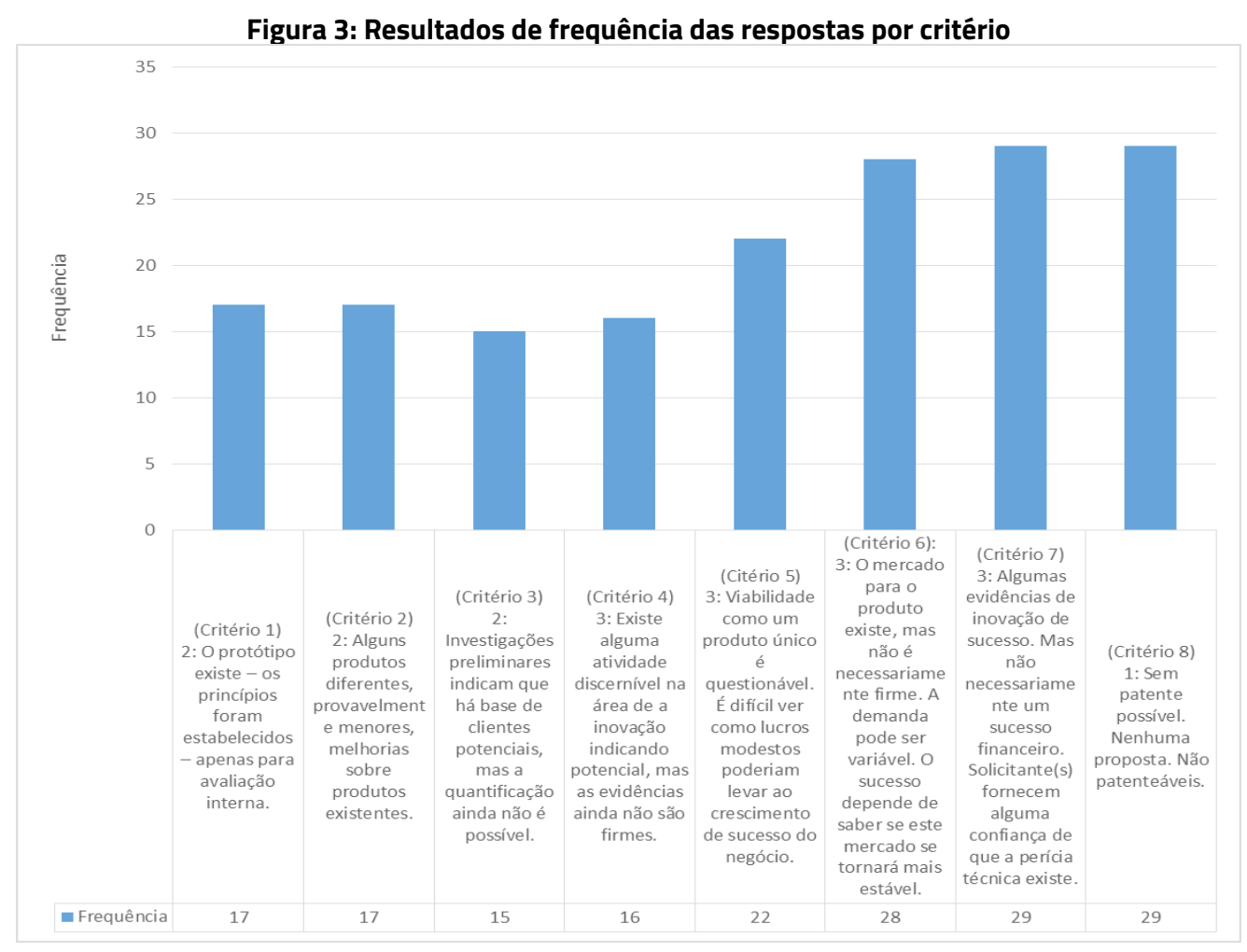

Fonte: Elaborado pelos autores.

Na Figura 3, pode-se perceber que os projetos de novos empreendimentos desenvolvidos pelos respondentes se encontram na etapa de criação, já que as maiores frequências na escala correspondem às 
menores posições crediveis de um empreendimento. De acordo com Tumelero, Marins e Carnaúba (2011) e Nogueira e Arruda (2015), na etapa de criação do novo empreendimento, o suporte de uma organizaçãomãe é fundamental para apoiar e proporcionar a articulação de redes de conhecimento necessárias. Além disso, é tipicamente nos estágios iniciais do empreendimento que o investidor-anjo investe seus recursos em troca de participação societária temporária e preferencial (BOTELHO; DIDIER; RODRIGUEZ, 2006). Por isso, nesse momento inaugural, a instituição de ensino deveria aproximar-se dos idealizadores dos projetos e fornecer o suporte necessário para que as ideias pudessem ser implementadas, dando origem às spin-offs.

Nesta análise, os critérios 4 (momento de mercado), 5 (longevidade e repetibilidade de compras), 6 (existência de família de produtos) e 7 (histórico dos empreendedores) tiveram suas maiores frequências no ponto mediano 3, sendo estas as melhores posições. Dessa forma, pode-se afirmar que, de acordo com os respondentes, seus projetos para novos empreendimentos: (4) fazem parte de uma necessidade já existente de mercado, mas ainda sem evidências concretas; (5) se vistos como produtos únicos, não garantem repetibilidade da compra e longevidade do produto; (6) possuem longevidade na demanda de produtos, ainda que não seja firme; e (7) são formados por equipes com algumas evidências de inovação, porém sem necessariamente sucesso financeiro. O último critério, que trata da propriedade intelectual, foi o que teve a maior frequência na menor posição credivel, ou seja, trata-se, na maioria dos casos, de empreendimentos não patenteáveis na visão dos respondentes. Esses dados refletem que os projetos idealizados pelos egressos possuem estrutura, mas precisam de apoio para que se tornem negócios com alto potencial de crescimento (valorização) (BOTELHO; DIDIER; RODRIGUEZ, 2006).

A técnica estatística de análise fatorial (JOHNSON; WICHERN, 2002) também foi aplicada, possibilitando identificar três fatores latentes da análise. Esses fatores são os critérios 1 (risco tecnológico e comercial), 2 (nível de inovação de produto) e 3 (modo de satisfação de setor do mercado), apresentados, a seguir, na Figura 4. 
Figura 4: Análise estatística fatorial dos componentes principais

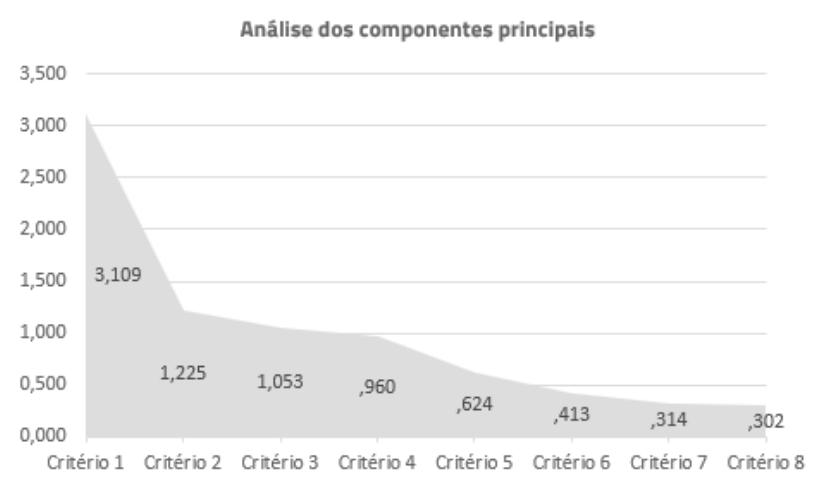

Fonte: Elaborado pelos autores.

Os fatores identificados na análise fatorial confirmam que os projetos são desenvolvidos internamente, sem a pretensão de consolidarem uma spin-off ou um empreendimento. Além disso, caracterizam-se no âmbito da inovação incremental e não apresentam uma base quantificável de clientes potenciais. Esses dados se contrapõem aos números do Sebrae (2013), que percebe as taxas de crescimento e sobrevivência dos empreendimentos como promissoras. A região, bem como a associação do curso dos entrevistados às TICs, também deveria representar um maior potencial de diferenciação de produtos e serviços, mas não é isso que ocorre, levando a crer que os empreendimentos tomados como base para a composição dos números apresentados pelo Sebrae (2013) não são originários de spin-offs acadêmicas.

Com a aplicação do método de ponderação proposto por De Coster e Butler (2005), foram identificados 26 registros de respostas cujo somatório foi maior que 25 pontos. Para 17 registros, o somatório foi menor que 25 pontos. Entretanto, na avaliação do produto em escala, apenas um registro teve 15 pontos na percepção dos respondentes. Assim, embora 60\% das avaliações tenham atingido 0 parâmetro indicado para que fosse considerado o financiamento, nenhuma das avaliações atingiu 25 pontos para o produto em escala (Figura 5). 
Figura 5: Avaliação da soma da pontuação e do produto em escala

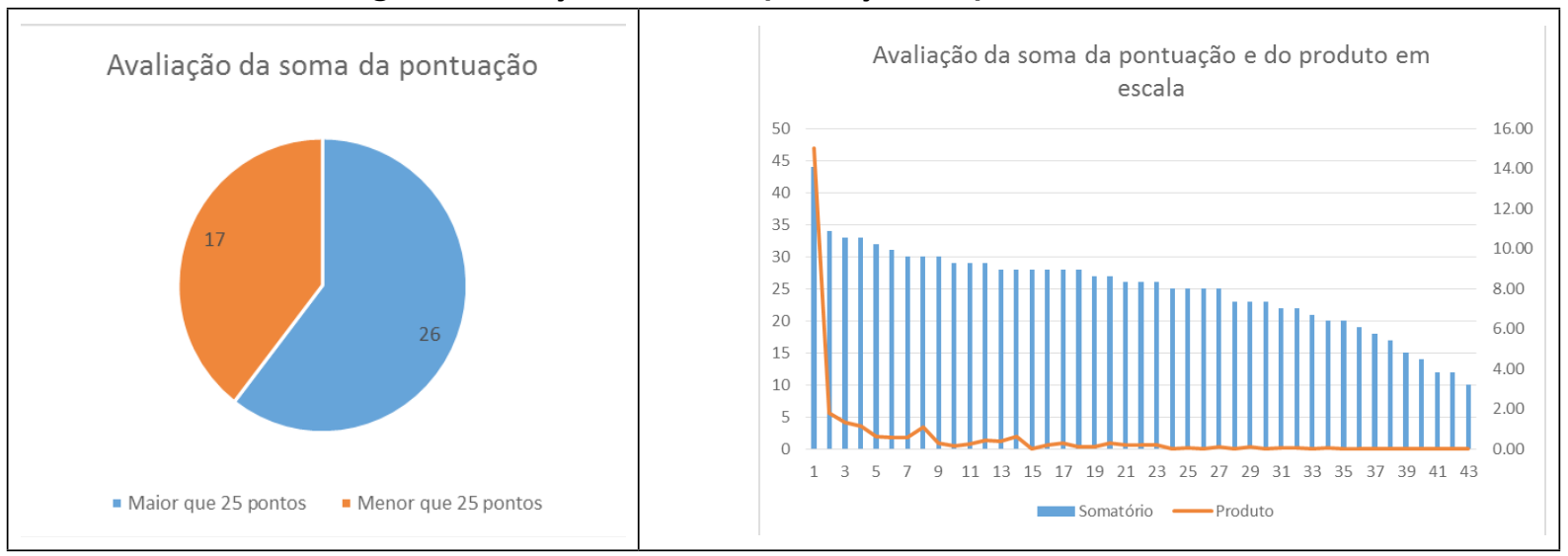

Fonte: Elaborado pelos autores.

No artigo de De Coster e Butler (2005), não foram identificadas as análises da avaliação da soma da pontuação e do produto em escala para que se pudesse realizar o comparativo. Entretanto, foi possível comparar os resultados da percepção dos respondentes brasileiros com a amostra de spin-offs acadêmicas do Reino Unido. Esse comparativo é apresentado na Figura 6.

Figura 6: Resultados comparativos - Média da pontuação

Resultados comparativos - Média da pontuação

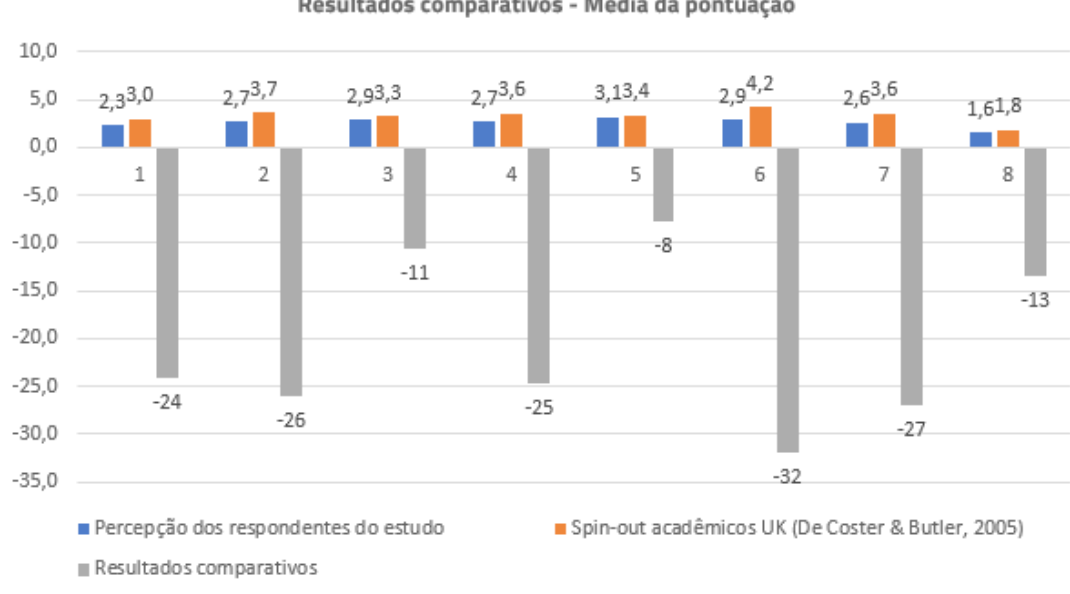

Fonte: Elaborado pelos autores. 
Na Figura 6, é possivel identificar as diferenças entre as duas amostras no que concerne à média da pontuação. Essa comparação foi realizada por meio da pontuação média da percepção dos respondentes, pelo valor médio das spin-offs acadêmicas do Reino Unido e pelo cálculo da diferença percentual. Após, foi realizado um teste de significância (teste $t$ ) para determinar quais desses resultados eram significativos ao nível de confiança de 95\%. Os resultados são apresentados na Tabela 3.

Tabela 3: Resultados do teste $t$

\begin{tabular}{|l|l|}
\hline \multicolumn{1}{|c|}{ Critérios } & \multicolumn{1}{|c|}{ Resultados teste $\boldsymbol{t}$} \\
\hline Critério 1 - Risco tecnológico e comercial & Sim \\
\hline Critério 2 - Nível de inovação de produto & Sim \\
\hline Critério 3 - Modo de satisfação de setor do mercado & Não \\
\hline Critério 4 - Momento de mercado & Sim \\
\hline Critério 5 - Longevidade e repetibilidade de compras & Não \\
\hline Critério 6 - Existência de família de produtos & Sim \\
\hline Critério 7 - Histórico dos empreendedores & Sim \\
\hline Critério 8 - Proteção de vantagem competitiva & Não \\
\hline
\end{tabular}

Fonte: Elaborado pelos autores.

Dos resultados significativos, a maior diferença foi percebida no critério 6 (existência de família de produtos). Os valores da pontuação média da percepção dos respondentes são 32\% inferiores ao valor médio das spin-offs acadêmicas do Reino Unido, resultado que pode ser atribuído a uma visão dos alunos focada no desenvolvimento técnico de seus projetos, sem levar em consideração a futura consolidação da empresa por meio da tecnologia incorporada à família de produtos. Assim, a contribuição desse achado reside no fato de que, para que surjam mais spin-offs originadas dos produtos dos trabalhos de conclusão de curso acadêmicos e, consequentemente, mais empreendimentos que se mantenham no mercado, é necessário que os projetos sejam desenvolvidos sob um olhar estratégico, com vistas à sua longevidade.

O critério 1, risco tecnológico e comercial, também foi apontado como significativo na comparação. Empreendimentos de alta tecnologia são inerentemente mais arriscados do que outras oportunidades de negócios, pois assumem o contexto inovador desde a concepção do negócio. Entretanto, os dados indicam que $38,6 \%$ dos projetos de novos empreendimentos dos respondentes ainda estão na etapa de protótipo, não tendo sido iniciada a produção, o que retrata a importância do acompanhamento de 
uma organização-mãe, para levar adiante as iniciativas válidas propostas pelos estudantes quando da conclusão do curso.

A pontuação inferior do critério 2, nível de inovação de produto, pode ser atribuída à concepção de produtos para o preenchimento de um nicho de mercado conhecido, o que faz com que se atue mais no nível de melhorias do que no nível da inovação propriamente dita. As spin-offs acadêmicas do Reino Unido têm pontuação mais elevada nesse critério em função da cultura de pesquisa intensiva em tecnologia desenvolvida nas universidades desse país.

Já a dificuldade no critério 4, momento de mercado, pode ser imputada à falta de profundidade nas análises de previsões de mercado. Por fim, o critério 7, histórico dos empreendedores, pode estar sendo comprometido por se tratar de estudantes recentemente formados, ou seja, com capacidade acadêmica ainda em formação, assim como pela falta de registros de projetos anteriores que possam comprovar a experiência do profissional.

De forma geral, as spin-offs acadêmicas do Reino Unido tiveram pontuações mais elevadas, pois são empresas já consolidadas, provenientes de trabalhos de pesquisa realizados em universidades. Nesse sentido, os resultados comparativos com esse país ressaltam a importância do desenvolvimento de projetos de novos empreendimentos com foco nos critérios determinantes do desempenho inicial de spinoffs acadêmicas pré-incubadas, como forma de consolidar os projetos desenvolvidos pelos estudantes no mercado, fomentando as oportunidades para investimento em iniciativas de empresas inovadoras.

As novas empresas de base tecnológica são responsáveis pela disseminação da inovação tecnológica e pelo estímulo industrial, tornando-se, portanto, tópicos atraentes de pesquisa no campo científico (ARANTES et al., 2019). Além disso, como observado recentemente, a taxa de mortalidade do empreendedorismo nascenteentreas empresas baseadas em nova tecnologia é significativamente superior à taxa de outras empresas (TORRECILLA-GARCÍA; ANDRÉS-REINA; SKOTNICKA, 2019). Essa taxa de falha está diretamente relacionada ao forte caráter de inovação e ao maior risco do implementar tecnologia no mercado, conforme mencionam Coster e Butler (2005). Por outro lado, há um número significativo de estudos que percebem o plano de negócios como uma ferramenta essencial à gestão da empresa, capaz de melhorar a criação de novas empresas de base tecnológica, bem como de propiciar sua consolidação e permanência do mercado. Este último aspecto é validado pela análise dos resultados obtidos a partir de questionários endereçados a empreendedores de tecnologia (TORRECILLA-GARCÍA; ANDRÉS-REINA; SKOTNICKA, 2019). 


\section{Considerações finais}

Por meio das análises realizadas, foi possível identificar que os projetos de novos empreendimentos desenvolvidos pelos respondentes como produto de seus trabalhos de conclusão de curso encontram-se na etapa de criação. Trata-se, assim, na visão dos respondentes, de projetos não patenteáveis, aspecto evidenciado pelo fato de que a proteção de vantagem competitiva foi o critério com a maior frequência na menor posição credivel.

Ademais, por intermédio da técnica estatística de análise fatorial, identificaram-se três fatores latentes da análise: risco tecnológico e comercial, nível de inovação de produto e modo de satisfação de setor do mercado. Já com a aplicação do método de ponderação, pôde-se notar que $60 \%$ das avaliações atingiram o parâmetro indicado para que o empreendimento fosse considerado como financiável; entretanto, nenhuma das avaliações atingiu 25 pontos para o produto em escala.

Na comparação dos resultados com as spin-offs acadêmicas do Reino Unido, observou-se que o critério com a maior diferença significativa foi "existência de família de produtos" (critério 6 - 32\% inferior ao valor médio das spin-offs acadêmicas do Reino Unido). Esse resultado pode ser atribuído a uma visão dos alunos focada no desenvolvimento técnico de seus projetos.

A importância deste estudo reside no fato de que, embora as inovações associadas às TICs estejam sendo amplamente discutidas e apoiadas, a sobrevivência das startups brasileiras depende da criação de mecanismos que fomentem a integração e geração de negócios entre seus múltiplos participantes. Isso passa pela criação de mecanismos que aproximem as linhas de pesquisa científica com a implementação de novos empreendimentos, resultantes de um esforço suportado pela organização-mãe. Os resultados dessa integração podem, consequentemente, sustentar projetos de novos empreendimentos que tenham menor risco e maior viabilidade para se manterem no mercado e que, de fato, atinjam o crescimento sustentável.

Assim, as contribuições deste estudo para o campo da Administração refletem a importância do desenvolvimento de práticas que promovam a aproximação da pesquisa acadêmica com as atuais demandas da sociedade. Como limitações desta investigação, pode-se citar o fato de ter sido realizada apenas a partir de projetos de novas empresas de base tecnológica - spin-offs acadêmicas - desenvolvidos por alunos.

Como sugestão de pesquisas futuras, da mesma forma como feito no Reino Unido, empresas da comunidade sem nenhuma conexão com a universidade poderiam ser analisadas, como modo de oferecer uma base adicional de comparação entre os fatores determinantes do desempenho inicial de spin-offs acadêmicas pré-incubadas. Igualmente, poderia ser executada uma pesquisa qualitativa com spin-offs acadêmicas, com o intuito de elucidar tais fatores na visão dos empreendedores e/ou investidores. 


\section{REFERÊNCIAS}

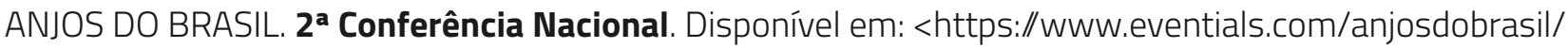
groups/2a-conferencia-nacional-anjos-do-brasil/>. Acesso em: 08 mar. 2015.

ANJOS DO BRASIL. $3^{\text {a }}$ Conferência Nacional. Disponivel em: <https://www.eventials.com/anjosdobrasil/ groups/3a-conferencia-nacional-anjos-do-brasil/>. Acesso em: 08 mar. 2015.

ARANTES, F. P.; CAETANO, M.; FREITAS DE PAULA, V. A.; BATISTA FREITAG, M. S. New independent technology-based firms: Differences from other NTBFs and future research agenda for technology innovation management. International Journal of Entrepreneurship and Innovation Management, 23 (1), pp. 46-71, 2019.

ARIAS, A. J.; VALBUENA, C. B. La gestión de conocimientos em entidades de conocimiento: el caso de los laboratorios académicos y de lãs empresas de base tecnológica en Europa. Pensamiento y Gestión. Universidad Del Norte, n. 22, p. 168-190, 2007.

BATHELT, H.; KOGLER, D. F.; MUNRO, A. K. A knowledge-based typology of university spin-offs in the context of regional economic development. Technovation, v. 30, p. 519-532, 2010.

BESSANT, J.; TIDD, J. Inovação e Empreendedorismo. [Recurso eletrônico]. Tradução Elizamari Rodrigues Becker, Gabriela Perizzolo, Patrícia Lessa Flores da Cunha. Porto Alegre: Bookman, 2009.

BOTELHO, A. J. J.; DIDIER, D.; RODRIGUEZ, V. Impulsionando o Take-off da Inovacao no Brasil: O Investidor Anjo. Proc. Enanpad. Salvador, Bahia, 2006.

CARAYANNIS, E. G.; ROGERS, E. M.; KURIHARA, K.; ALLBRITTON, M. M. High-Technology spin-offs from government R\&D laboratories and research universities. Technovation, v. 18, n. 1, p. 1-11, 1998.

CLARK, B. Delineating the character of the entrepreneurial university. Higher Education Policy, 17, p. 355-370, 2004.

CLARK, B. Sustaining Change in Universities: Continuities in Case Studies and Concepts. Tertiary Education and Management, v. 9, n. 2, p. 99-116, 2003.

CRUZ, F. Governo lança Programa TI Maior para estimular produção de softwares no Brasil. Agência Brasil: Empresa Brasil de Comunicação. Ago, 2012. Disponivel em: <http://memoria.ebc.com.br/agenciabrasil/noticia/2012-08-20/governo-lanca-programa-ti-maior-para-estimular-producao-de-softwares-no-brasil>. Acesso em: 08 mar. 2015. 
DAHLSTRAND, A. L. Technology-based entrepreneurship and regional development: the case of Sweden. European Business Review. Bradford, v. 19, n. 5, p. 373-386, 2007.

DE CLEYN, S. H.; BRAET, J.; KLOFSTEN, M. How human capital interacts with the early development of academic spin-offs. International Entrepreneurship and Management Journal, 11 (3), pp. 599-621, 2015

DE COSTER, R.; BUTLER, C. Assessment of proposals for new technology ventures in the UK: characteristics of university spin-off companies. Technovation, v. 25, p. 535-543, 2005.

DESIDÉRIO, P. H. M.; ZILBER, M. A. Barreiras no processo de transferência tecnológica entre agências de inovação e empresas: observações em instituições públicas e privadas. Revista Gestão \& Tecnologia, v. 14, n. 2, p. 101-126, 2014.

ERIKSSON, T.; KUHN, J. M. Firm spin-offs in Denmark 1981-2000: patterns of entry and exit. International Journal of Industrial Organization, v. 24, p. 1021-1040, 2006.

FREITAS, J. S.; GONÇALVES, C. A.; CHENG, L. C.; MUNIZ, R. M. Configurações Parcimoniosas Explicativas do Desempenho Inicial de Spin-Offs Acadêmicos Pré-Incubados. XXXIV Encontro da ANPAD. Rio de Janeiro, 2010.

GOMPERS, P. A. Optimal investment, monitoring, and the staging of venture capital. Journal of Finance, V. 50, p. 1461-1490, 1995.

HAIR, J. F.; BLACK, W. C.; BABIN, B. J.; ANDERSON, R. E.; TATHAM, R. L. Análise multivariada de dados. Bookman Editora, 2009.

HILL, M. M.; HILL, A. Investigação por questionário. 2. ed. Lisboa: Sílabo, 2012.

ITURRIAGA, F. L.; CRUZ, N. M. Antecedents of corporate spin-offs in Spain: A resource-based approach. Research Policy, v. 37, p. 1047-1056, 2008.

JOHNSON, R. A.; WICHERN, D. W. Multivariate Statistical Analysis. Prentice Hall, 2002.

MEYER, J. Welcome to entrepreneur country. London: Constable, 2012.

MUSTAR, P.; RENAULT, M.; COLOMBO, M. G.; PIVA, E.; FONTES, M.; LOCKETT,

A.; WRIGHT, M.; CLARYSSE, B.; MORRAY, N. Conceptualising the heterogeneity of research-based spinoffs: A multi-dimensional taxonomy. Research Policy, v. 35, p. 289-308, 2006. 
NOGUEIRA, V.; ARRUDA, C. Causas da mortalidade das startups brasileiras: como aumentar as chances de sobrevivência no mercado. Dom: a revista da Fundação Dom Cabral. n. 25, p. 26-33, 2015.

OECD. Manual de 0slo. (2005). Diretrizes para coleta e interpretação de dados sobre inovação. 3. ed. Produção: ARTI e FINEP. Trd.: Flávia Gouveia. 184 p.

PÉREZ, M. P.; SÁNCHEZ, A. M. The development of university spin-offs: early dynamics of technology transfer and networking. Technovation, v. 23, p. 823-831, 2003.

PISCIONE, D. P. Os segredos do vale do silício: O que você pode aprender com a capital mundial da inovação. HSM Editora, 2014.

POPONI, S.; BRACCINI, A. M.; RUGGIERI, A. Key success factors positively affecting organizational performance of academic spin-offs. International Journal of Innovation and Technology Management, 14 (5), 2017.

RIES, E. The lean startup: How today's entrepreneurs use continuous innovation to create radically successful businesses. Crown Books, 2011.

SAEMUNDSSON, R. J. Technical knowledge-seeking in a young and growing technologybased firm: incentives and direction. International Journal of Innovation Management, v. 8, n. 4, p. 399-429, 2004.

SANTOS, S. A.; CUNHA, N. C. V. (Org.). Criação de empresas de base tecnológica: conceitos, instrumentos e recursos. Maringá: Unicorpore, 2004.

SEBRAE. Sobrevivência das empresas no Brasil. Brasilia: coleção estudos e pesquisas. 2013. Disponível em: <http://www.sebrae.com.br/Sebrae/Portal\%20Sebrae/Anexos/Sobrevivencia_das_empresas_no_ Brasil=2013.pdf>. Acesso em: 12 jun. 2016.

STEFFENSEN, M.; ROGERS, E. M.; SPEAKMAN, K. Spin-offs from research centers at a research university. Journal of Business Venturing, v. 15, p. 93-111, 1999.

STERNBERG, R. Success factors of university-spin-offs: Regional government support programs versus regional environment. Technovation, v. 34, p. 137-148, 2014.

TORRECILLA-GARCÍA, J. A.; ANDRÉS-REINA, M. P.; SKOTNICKA, A. G. The relevance of business plan as a management tool for tech entrepreneurs. Espacios, 40, (3), 28, 2019. 


\section{Gestãoe \\ Desenvolvimento}

TUMELERO, C.; MARINS, C.; CARNAÚBA, A. C. Estudo do conhecimento em empresas de base tecnológica incubadas: proposição de um modelo conceitual integrativo. Revista Gestão \& Tecnologia, v. 11, n. 1, p. 2-17, 2011.

VENKATARAMAN, S. Regional transformation through technological entrepreneurship. Journal of Business Venturing. Nova lorque, v. 19, n. 1, p. 153-167, 2004. 